\title{
Opportunities to improve the efficiency of design and construction
}

\author{
Angelina Rybakova* and Pavel Kagan \\ Moscow State University of Civil Engineering, Yaroslavskoe shosse, 26, Moscow, 129337, Russia
}

\begin{abstract}
This article discusses the current opportunities of «high-speed construction», which are based on technological, organizational and managerial approaches. For each acceleration approach under study, the mechanisms of action, advantages and disadvantages, as well as its distribution and scope, are identified. The most detailed method of «highspeed construction» based on the combination of design and construction works. The formation of this approach and the tools for its implementation are considered in detail. In this regard, the aim of the work is a detailed consideration of all modern methods of «high - speed construction», and the task-their structuring and interconnection. In the course of the study, the method of analyzing the directions of improving the efficiency of design and construction was applied. As a result, algorithms and tools for accelerating construction are formulated, as well as the impact of BIMtechnology services.
\end{abstract}

\section{Introduction}

The modern world of construction is constantly evolving, there are new directions and new ideas to improve existing technologies. However, globally the industry is still dominated by conservatism and slow compared to other areas of development. Due to the large number of participants in construction and various types of work, it is necessary to improve several areas, which, in turn, accumulates the total development of the industry, and at the same time inhibits its constant divergences or mutual exclusion.

For the maximum effect of innovations in construction, it is important to determine the right way and procedure that will ensure the best result of the functioning of the entire construction system. This issue is the most important, as its solution includes a multicriteria analysis of indicators, the formation of solutions to existing problems and adequate response to all changes. Thus, it is necessary to correctly identify the problems that arise in the course of improvement or development, to formulate ways to solve them and specific actions for early implementation, as well as to develop methods for monitoring and analyzing the effectiveness of the work done.

One of the problematic issues of construction is the long term implementation of projects. The main reasons for the increase in time are technological features, problems with financing and bureaucracy. There are other factors, but they are less significant. In

\footnotetext{
${ }^{*}$ Corresponding author: angelinaribakova@yandex.ru
} 
recent years, the total period of construction has decreased slightly, which leads to the lack of a suitable way or effective way to speed up construction.

\section{Equations and mathematics}

\section{Directions of development of construction industry}

Based on the reasons for the significant timing of construction projects, it is possible to determine ways to accelerate them on the basis of various technologies (methods, methods, tools). In many processes, the main method of acceleration is the use of finished materials or pre-formed components in the desired structure. Thus, the parallel execution of works is carried out in time. Usually, this approach is applied to construction and erection works $(\mathrm{CEW})$, however, with the spread of modern technologies can be performed in parallel and other types of work. In a generalized form, the directions of innovative development to accelerate construction can be represented as follows (Fig.1).

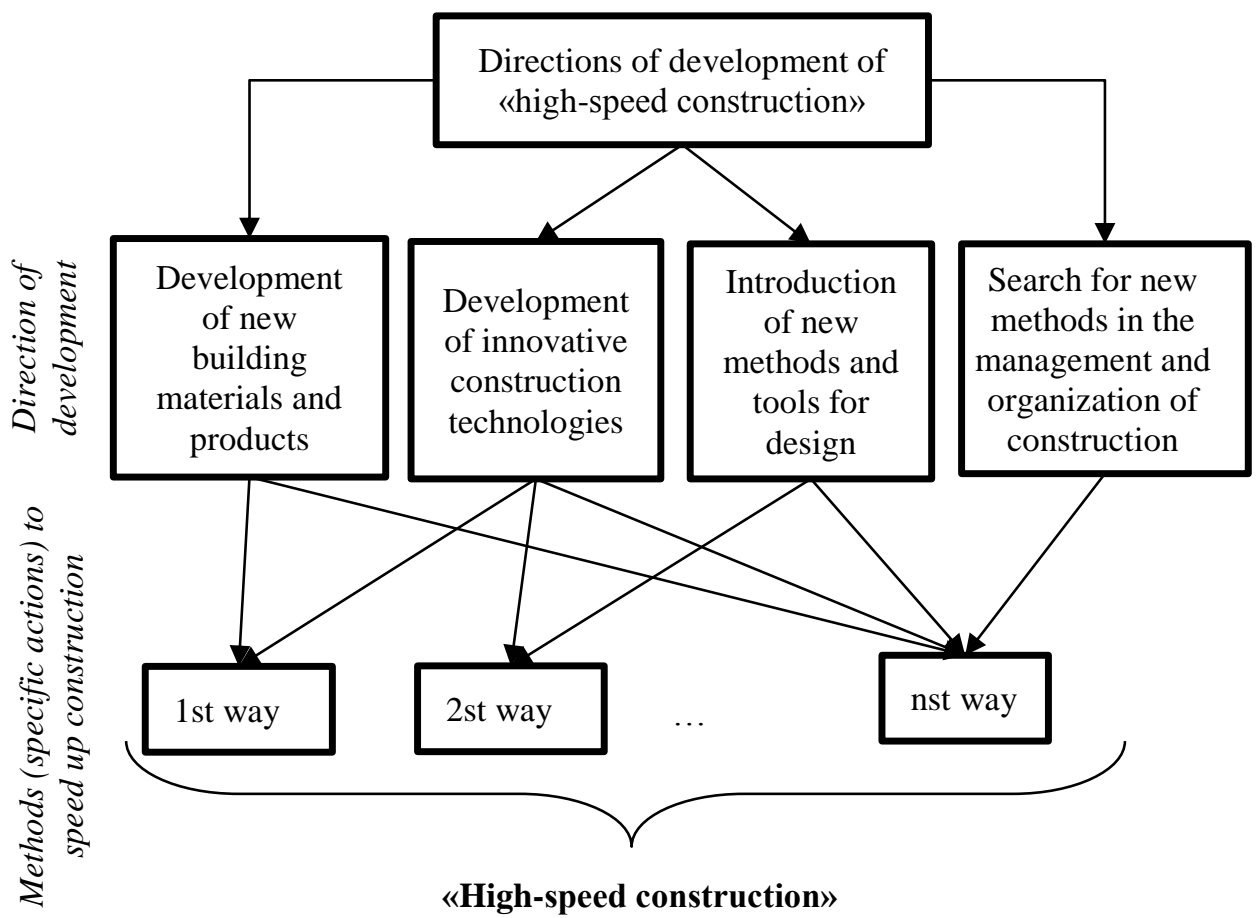

Fig. 1. Directions of development of construction industry

The solution of any construction problem is rarely possible only in one of the following ways, usually it is a combination of several solutions or their modifications depending on the specific situation and the specifics of the object. Similarly, actions are formed and to reduce the construction time. As a rule, the main direction is determined, which will be supplemented by other ways to improve as research or search for a solution.

Very common methods of accelerating construction, which today are often used in the construction of simple objects, are new ways of performing construction and technological works on the installation of basic structural elements. The basis of this type of methods is 
the complementarity of new construction technologies and building materials or products. However, for maximum efficiency, it is important to apply a different approach to design and construction management.

\section{Improving the efficiency of management and organization of construction}

At the moment it is possible to allocate several methods of acceleration by means of tools of construction and installation works for the adequate cost of realization, rather widespread for construction of simple objects. The main directions that have been tested and thoroughly worked out, can be grouped as follows:

1. Use of heat-efficient blocks.

One of the new construction methods based on saving time and money is the use of large heat - efficient blocks. They consist of two concrete layers, between which there is a ten-centimeter layer of expanded polystyrene. A total of three layers, connected by a reinforcing fiberglass rods. This technology allows to reduce the duration of construction, as well as to obtain a wall that is virtually indistinguishable from its reinforced concrete counterpart.

2. Modular technology.

The essence of the technology of modular buildings is the Assembly of the finished module from the elements of the metal frame produced at the plant: floors, walls, bases. Laying of communications, installation of Windows and doors and interior decoration is made for each module separately. The finished module is sent to the construction site, where it is installed on the Foundation. Due to the implementation of most of the work on the collection of the module and the effect of accelerating construction.

3. Frame technology.

The main advantage of frame construction technology is a small thickness of the enclosing structure, which provides a lower cost. The basis of construction is a wooden and filled with soft insulation supporting frame. This reduces the duration of construction, as the frame panels are made in advance in the factory and immediately ready for installation.

4. Use of permanent formwork.

The basis of this technology is the use of wall blocks made of special polystyrene foam as a permanent formwork. From these blocks the hollow wall is mounted and immediately filled with reinforcement and concrete mix. As a result of this technological operation, a monolithic three - layer wall with heat and sound insulation layers of expanded polystyrene is formed several times faster than the analogue of the conservative approach.

5. Lego-technology.

This technology was first used in the construction of twin towers in new York. This technology is based on the principle of construction designer Lego - allows the same «parts» to build buildings of different configurations and volumes. The frame of reinforced concrete is a reliable basis of such a house. The monolithic frame is erected in the tunnel formwork, and outside the frame mounted hinged three-layer panels. Thus, high speed of construction is provided. 


\section{Formation of «high-speed construction» approaches}

All of these methods are combined with pre-manufactured innovative products and designs, for which new design approaches, appropriate construction technologies and, consequently, other ways of organizing a certain type of CEW are defined. In a generalized form, the formation of these methods can be represented as a scheme (Fig. 2). However, a more detailed study of all methods, you can see a large number of differences, advantages and disadvantages that determine the specifics of each method.

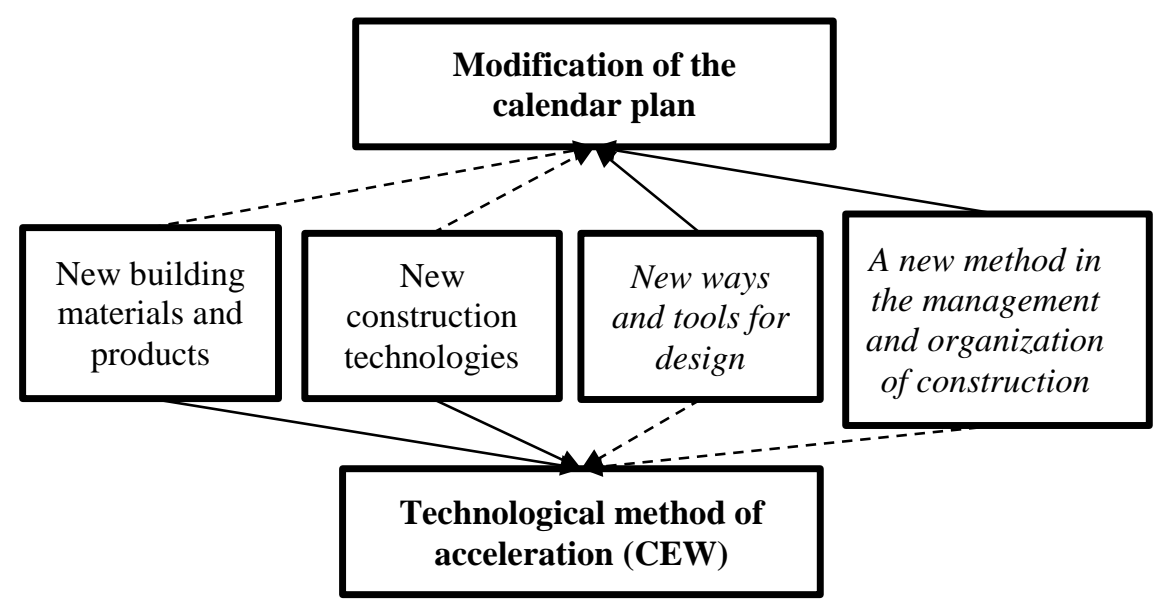

Fig. 2. The direction of the acceleration at the stage of scheduling and through CEW

A large number of options for accelerating construction can be identified at the stage of scheduling. All areas of this type are largely formed on the basis of new design tools and improving the efficiency of management and organization of construction with individual elements of new technologies or materials (Fig. 2).

There are different ways of combining or interconnecting activities. This direction is very attractive for research, which leads to the constant emergence of new, more effective ways. Common models of the acceleration of the construction by modifying the schedule:

- Minimization of critical path,

- Overlap of the individual steps,

- $\quad$ Parallel execution of works,

- Combination of the main and related specialties,

- Combining the work of several related projects,

- Maximum interaction of technologically related works (the result of previous work is a condition for further work).

For the most effective organization of work, each of these methods is more appropriate to combine with each other depending on the specifics of the object, the availability of labor and material resources, territorial and other conditions. In any case, in order to apply a particular method, it is necessary to conduct a detailed study of its implementation and possible consequences, as well as to perform calculations confirming its potential effectiveness. If a method or group of methods is used without proper justification and calculations, the consequences may be negative. 
Another direction, newer and less demanding - is the combination of design and construction works. This approach, similar to calendar planning, is based on new design tools and new ways of organizing construction. Depending on the work performed, design or construction, the advantage of the method is determined in the formation of the approach. The technological component in this case has a methodical character, but it can not be ignored (Fig. 3)

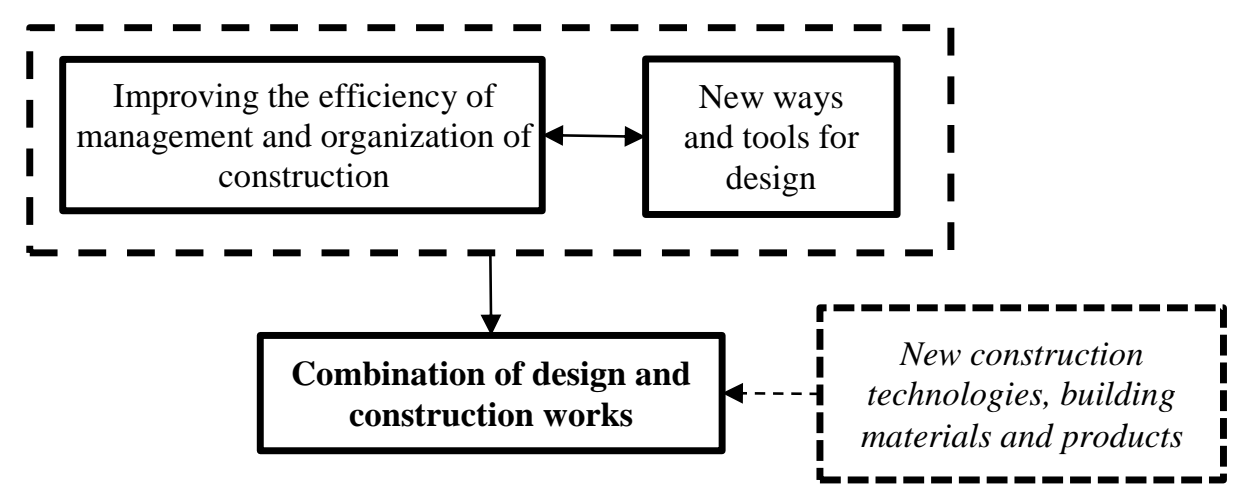

Fig. 3. «Combination» of design and construction works

\section{Organization of «combination» of design and construction works}

It is rather difficult to classify or single out the components of this direction due to the lack of regulatory approved regulations on acceleration and insufficient study of this issue. The main task of this approach is to determine the list of design and construction works that can be performed in parallel, as well as to determine the sequence of these combined works to achieve maximum efficiency.

If we consider the whole complex of design and construction works, we can distinguish a simple logical way of separation: supporting structures and technological component. After the development of structural sections and passing the examination, nothing prevents to proceed with the installation of bearing elements and the simultaneous design of engineering systems and other sections. The need to pass the examination of the technological part is quite difficult to determine and requires additional research on this issue.

The current two-stage design (Project and working documentation) does not reduce the time, but rather contributes to their increase. This is due to the fact that the boundary between them is rather blurred, when designing each new object, disputes are conducted on the issue of detailing each stage, the transition to construction is not ensured after obtaining a positive conclusion of the Project stage, and, according to the law, a number of additional procedures for obtaining construction permits.

In addition to the design and construction stages in the approach of «combining works» it is logical to consider pre-design work, including the collection of initial permits (IRD). Similar to the «combination» of the design stage and construction, you can try to combine certain steps of pre-design and design work. Options for the separation of these stages can be identified enough, in contrast to the design and construction model. This is due to the fact that, depending on the specifics, category and scale of the object, pre-project works and their significance will differ significantly. The composition of the design work does not change so much. 
As a result, it is potentially possible to parallelize the implementation of certain types of pre-design, design and construction works, but the question of their rational and effective combination will always be acute for each object. For a more detailed study and comparison of the «conservative» sequence of works and the proposed «accelerated» scheme, it is possible to present the process in the form of a combination of three main stages (Fig. 4, Fig. 5).

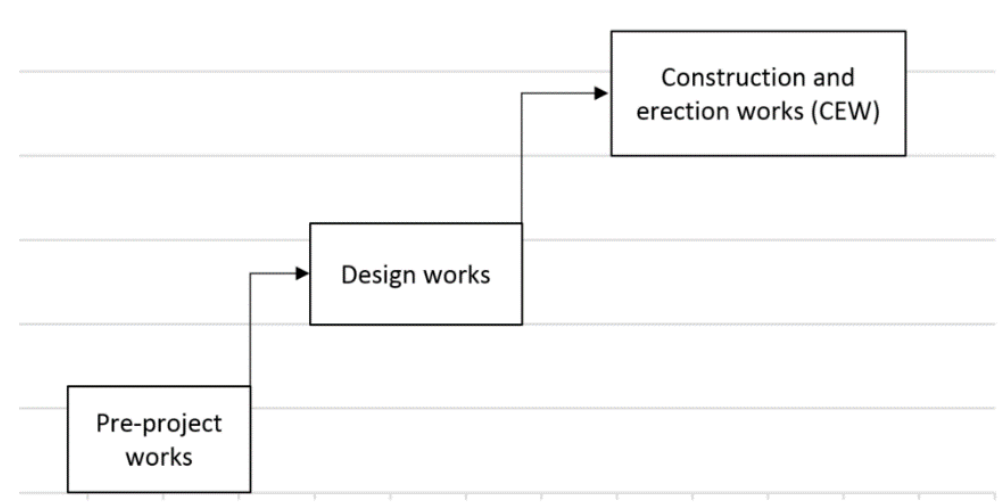

duration, $\mathrm{t}$

Fig. 4. An existing sequence

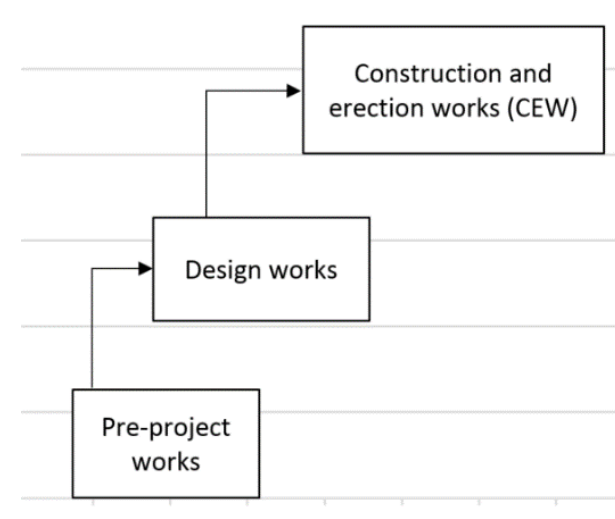

duration, $\mathrm{t}$

Fig. 5. Express the sequence

Thus, the combination of the main stages can give a total effect on the timing of implementation. The exact values of the reduction of time indicators can be obtained with a more detailed calculation of the indicators of the calendar plan, taking into account the effective combination of certain types of work at each stage. Therefore, the most important task is to determine the works that can be combined, clarify their relationships and develop detailed versions of the calendar plan.

For a speedy solution of such tasks and their implementation, you can use the automation tools. The most effective on the whole cycle of work are software complexes of BIM-technologies. When developing a project in one of these programs, the time is 
significantly reduced, and when using cloud BIM-services due to the facilitated interaction between all construction participants, the time of access to information is reduced significantly. Thus, the use of BIM-technologies in solving the problem of accelerated construction contributes to the search for solutions for effective alignment, and helps to implement the chosen solution.

\section{Conclusions}

For various participants of construction issues of acceleration of production of works are important and relevant. The considered methods of development of «high-speed construction», namely, the combination of design and construction stages, aim not only to reduce the time, but as a consequence, to obtain economic effect from the early commissioning of the object. A more complete study can be identified and other advantages: efficient use of human and material resources, early binding draft model applications to climate and other features of the construction site, minimizing loss of profits, expeditious solution to public and socially important issues, etc. Along with the expected positive effect in the project construction, benefits and related areas. Thus, «highspeed construction» with the most rational use of its methods and tools, allows to solve a number of problems: from construction and technological to socio-economic. Therefore, the choice, development and implementation of specific methods of «high-speed construction» contributes to the total positive effect of all dependent areas of activity and development.

This work was financially supported by Ministry of Science and Higher Education of the Russian Federation (\#NSh-3492.2018.8).

\section{References}

1. Asnina A. J., Ali, F. A. N., Likhacheva N. Yu. INFORMATION SUPPORT of DECISION-MAKING IN CONSTRUCTION // Scientific Herald of the Voronezh state University of architecture and construction. Series: Information technologies in construction, social and economic systems. 2014. No. 2. C. 76-79.

2. B. Pavel B., V. Kulikov V.: Information modeling of urban planning development, Applied Mechanics and Materials 409-410, 951-954 (2013)

3. Garyaev N. A. Rybakova A. O. Cloud technologies of interaction at design and construction // BST:Bulletin of construction equipment. 2018 № 4 (1004). P. 28-31.

4. K. Anatolevna, K. Borisovich, Management systems of urban planning, International, Journal of Applied Engineering Research, 10, 43456-43460 (2015)

5. Kagan P.: Management, mechanization and automation of work in the construction of high-rise buildings, MATEC Web of Conferences 170, 01071 (2018), https://doi.org/10.1051/matecconf/201817001071

6. Kagan P.: Monitoring of the development of urban areas with the use of information technology, MATEC Web of Conferences 193, 05031 (2018), https://doi.org/10.1051/matecconf/201819305031

7. Kagan P.: THE ENGINEERING COMMUNICATION NETWORKS - THE ISSUES OF USE OF STANDARDS FOR THE INFORMATION REPRESENTATION IN DESIGN, CONSTRUCTION AND OPERATION. Procedia Engineering 25, 261-265 (2016)

8. Korenyugina I. V., Dolgikh M. V., Dmitrieva N. Oh. The main directions of innovative development of the construction industry of the Russian Federation / / Science 
yesterday, today,tomorrow: sat. XLVIII international. scientific.- prakt. Conf. № 7 (41). - Novosibirsk: Sibak, 2017. - P. 63-70.

9. Nikolay Garyaev and Angelina Rybakova Cloud interaction technologies in the design and construction // MATEC Web of Conferences. 2018 V. 170 Article number 1076

10.P. Kagan, T. Barabanova, The Formal Language for Describing Technological Processes in Construction, Computing in Civil and Building Engineering, 2232-2237 (2014)

11. Sandown R. N. The effectiveness of combining work on the main and related disciplines in the construction // proceedings of Tuva state University the proceedings of the annual scientific-practical conference of teachers, staff, and graduate students Tougu dedicated to the 65th anniversary of higher pedagogical education in the Republic of Tuva and the 95th anniversary of the formation of the Tuva people's Republic. Of the «Tuvan state University». 2016. P. 219-221. 